\title{
Efficacy of a Universal Brief Intervention for Violence Among Urban Emergency Department Youth
}

\author{
Patrick M. Carter, MD, Maureen A. Walton, MPH, PhD, Marc A. Zimmerman, PhD,
} Stephen T. Chermack, PhD, Jessica S. Roche, MPH, and Rebecca M. Cunningham, MD

\begin{abstract}
Background: Violent injury is the leading cause of death among urban youth. Emergency department (ED) visits represent an opportunity to deliver a brief intervention (BI) to reduce violence among youth seeking medical care in high-risk communities.

Objective: The objective was to determine the efficacy of a universally applied BI addressing violence behaviors among youth presenting to an urban ED.

Methods: ED youth (14 to 20 years old) seeking medical or injury-related care in a Level I ED (October 2011-March 2015) and screening positive for a home address within the intervention or comparison neighborhood of a larger youth violence project were enrolled in this quasi-experimental study. Based on home address, participants were assigned to receive either the 30-minute therapist-delivered BI (Project Sync) or a resource brochure (enhanced usual care [EUC] condition). The Project Sync BI combined motivational interviewing and cognitive skills training, including a review of participant goals, tailored feedback, decisional balance exercises, role-playing exercises, and linkage to community resources. Participants completed validated survey measures at baseline and a 2-month follow-up assessment. Main outcome measures included self-report of physical victimization, aggression, and self-efficacy to avoid fighting. Poisson and zero-inflated Poisson regression analyses analyzed the effects of the BI, compared to the EUC condition, on primary outcomes.
\end{abstract}

Results: A total of 409 eligible youth ( $82 \%$ participation) were enrolled and assigned to receive either the BI $(n=263)$ or the EUC condition $(n=146)$. Two-month follow-up was $91 \%(n=373)$. There were no significant baseline differences between study conditions. Among the entire sample, mean $( \pm$ SD) age was $17.7( \pm 1.9)$ years, 60\% were female, 93\% were African American, and 79\% reported receipt of public assistance. Of participants, 9\% presented for a violent injury, 9\% reported recent firearm carriage, 20\% reported recent alcohol use, and 39\% reported recent marijuana use. Compared with the EUC group, participants in the therapist BI group showed self-reported reductions in frequency of violent aggression (therapist, $-46.8 \%$; EUC, $-36.9 \%$; incident rate ratio $[\mathrm{IRR}]=0.87 ; 95 \%$ confidence interval $[\mathrm{CI}]=0.76$ to 0.99 ) and increased self-efficacy for avoiding fighting (therapist, $+7.2 \%$; EUC, $-1.3 \%$; IRR $=1.09$; $95 \%$ $\mathrm{CI}=1.02$ to 1.15 ). No significant changes were noted for victimization.

Conclusions: Among youth seeking ED care in a high-risk community, a brief, universally applied BI shows promise in increased self-efficacy for avoiding fighting and a decrease in the frequency of violent aggression.

From the University of Michigan Injury Center (PMC, MAW, MAZ, JSR, RMC), the Department of Emergency Medicine (PMC, JSR, RMC), and the University of Michigan Addiction Research Center, Department of Psychiatry (MAW, STC), University of Michigan School of Medicine, Ann Arbor, MI; the Michigan Youth Violence Prevention Center (PMC, MAW, MAZ, JSR, RMC) and the Department of Health Behavior \& Health Education (MAZ, RMC), University of Michigan School of Public Health, Ann Arbor, MI; the Department of Veterans Affairs, Center for Clinical Management Research, Ann Arbor VA Healthcare System (STC), Ann Arbor, MI; and the Department of Emergency Medicine, Hurley Medical Center (RMC), Flint, MI.

Received March 16, 2016; revision received May 10, 2016; accepted May 18, 2016.

Presented at the Society for Academic Emergency Medicine Annual Meeting, New Orleans, LA, May 2016.

This work was funded by CDC 5-U01-CE-001957-03, and in part by CDCP 1R49CE002099 and NIH/NIDA K23DA039341. The views in the manuscript do not necessarily reflect those of the funding agency. Dr. Carter authored the first draft of this manuscript. No honoraria, grants, or other forms of payment were received from any of the coauthors for producing the manuscript.

The authors have no potential conflicts to disclose.

ClinicalTrials.gov identifier NCT02586766.

Supervising Editor: Mark B. Bycyk, MD.

Address for correspondence and reprints: Patrick M. Carter, MD; e-mail: cartpatr@med.umich.edu. 
$\mathrm{Y}$ outh violence is a significant public health problem. Homicide rates among U.S. youth are 14 times higher than those among youth in other high-income countries. ${ }^{1}$ Violent injury is the leading cause of death for urban minority youth and responsible for more than 600,000 adolescent emergency department (ED) visits annually. ${ }^{2}$ Nationwide, $25 \%$ of high school-age students report fighting in the past 12 months and 18\% report carrying a weapon in the past month. ${ }^{3}$ Societal costs associated with this violence are substantial, estimated at more than $\$ 4$ billion for acute medical care and $\$ 32$ billion for lost wages/productivity annually. ${ }^{4}$ Developing effective prevention programs for at-risk youth is a significant focus of public health efforts, ${ }^{5-11}$ especially given data demonstrating that adolescent violence involvement is linked with negative long-term health and psychosocial outcomes, including substance abuse/dependence, anxiety/depression, posttraumatic stress disorder, incarceration, violent injury, and death. ${ }^{5,12-22}$

Urban EDs are an important, but underutilized setting for violence prevention. ${ }^{5}$ Prior data highlight that youth seeking ED care within urban settings have elevated rates of violence, as well as associated risk behaviors, including substance use, firearm possession, and weapon carriage. $^{23-26}$ Urban EDs also provide an opportunity to access traditionally difficult-to-reach adolescents, including uninsured/underinsured youth, as well as those without a primary care physician and those not regularly attending school. ${ }^{27,28}$ Prior studies have demonstrated the effectiveness of brief interventions (BIs) for the prevention of a range of injuryrelated risk behaviors, most commonly alcohol use. ${ }^{29-35}$ More recently, ED-based BIs have been expanded to incorporate violence prevention. ${ }^{36,37}$ Findings from the SafERteens study, a randomized control trial (RCT) conducted among ED adolescents screening positive for alcohol and peer violence demonstrated that a therapist-delivered BI significantly reduced peer aggression, peer victimization, dating victimization, and alcoholrelated consequences. ${ }^{36-38}$ While such selective interventions conducted among an at-risk population (i.e., youth with a history of alcohol use and prior violence) have been shown to be effective, researchers have not previously evaluated a BI to reduce violence behaviors among a universal population of ED youth living in neighborhoods with elevated levels of community violence. Such a universal prevention-based approach (i.e., addressing violence risk among all youth who are seeking ED care from a high-risk neighborhood) has the potential to substantially effect the public health of urban communities, especially if the BI is designed to be delivered seamlessly during an ED visit.

Similar to other urban communities with elevated rates of crime, violence, and poverty, youth violence is a significant problem in Flint, Michigan. ${ }^{39}$ Since 2011, the Michigan Youth Violence Prevention Center (YVPC) has been working with community partners to implement a comprehensive youth violence prevention program. ${ }^{40}$ This study evaluates the ED-based component of this program focused on an individual level intervention addressing youth populations. Specifically, this article examines the efficacy of a therapist-delivered universal BI (Project Sync) compared to an enhanced usual care (EUC) condition in reducing violence behaviors among adolescents seeking ED care at a Level I trauma center within discrete geographical regions of Flint. It was hypothesized that youth receiving the BI would decrease self-reported violence behaviors (aggression, victimization) and increase self-efficacy for avoiding fighting compared to youth in the EUC group who did not receive the $\mathrm{BI}$.

\section{METHODS}

\section{Study Design and Setting}

Project Sync is a 5-year quasi-experimental trial testing the efficacy of a BI compared to an EUC condition for a universal population of youth seeking medical or injuryrelated care in the Hurley Medical Center (HMC) ED in Flint, Michigan. The study was one component of a multifaceted youth violence prevention program ${ }^{40}$ testing six interventions within a focused intervention neighborhood compared to a comparison neighborhood. Interventions were designed so as not to overlap. This study was the only intervention to focus on individual counseling of youth in an ED regarding their involvement in violence. Other interventions focused on improving social interactions (e.g., parent/adult mentoring relationships) or environmental factors (e.g., community policing, clean and green initiatives); only one other intervention was focused at the individual level, but utilized a school-based curriculum to focus on positive youth development among a younger adolescent population. Both neighborhoods were matched on multiple sociodemographic characteristics, including the percentages of African American/Hispanic residents, owner-occupied housing, high school graduates, and residents below the poverty level. The neighborhoods were also matched on adolescent population counts, median household income, and violent crime rates. The UM and HMC institutional review boards approved all study procedures; a Centers for Disease Control and Prevention certificate of confidentiality was also obtained.

\section{Recruitment}

Recruitment (October 2011-March 2015) occurred within the HMC ED between 2:30 PM and 10:00 PM, 7 days a week, excluding holidays, with additional morning (8:30 AM-4:00 PM) and midday (11:30 AM7:00 PM) shifts as scheduling allowed. Of note, the intervention neighborhood was purposefully oversampled to meet the aims of the larger YVPC project (i.e., to interact with as many youth from the intervention neighborhood as possible). 


\section{Eligibility}

ED patients (14-20 years old) were identified using electronic medical records and approached in waiting rooms/treatment spaces. Participants screening positive for a home address within the intervention or comparison neighborhood were eligible for inclusion. Patients were excluded if they were unable to provide informed consent due to medical (e.g., altered mental status) or psychiatric reasons (e.g., cognitive impairment), or if they were presenting for a sexual assault and/or suicidal ideation/attempt. Patients were also excluded if they were $<18$ years old and seeking care without a parent/ guardian present (or they were unavailable for phone consent), in police custody, or if they were unable to self-administer the survey or participate in the BI (e.g., non-English speaking).

\section{Study Protocol}

Following written consent (or assent with parent/guardian consent), participants self-administered a 25-minute computerized baseline survey (\$20 remuneration) via touchscreen tablet. Participants were assigned to a study condition based on home address; those residing in the intervention neighborhood received the $\sim 30$-minute $\mathrm{BI}$, while those in the comparison neighborhood received a resource brochure (i.e., EUC condition). Participants self-administered a computerized follow-up assessment at 2 months (\$25 remuneration). Follow-up visits, which were arranged at the time of the baseline visit, were primarily conducted in person $(n=357$; $95.7 \%$ ) in a convenient location (e.g., ED/hospital, home visit, community location). Of in-person follow-ups, $77 \%$ occurred at the study hospital. Participants were sent a combination of reminders for follow-up appointments, including postcards, phone calls, and texts to enhance attendance.

\section{Measures}

Sociodemographics. Demographic and socioeconomic characteristics (e.g., age, sex, race/ethnicity, marital status, living situation, public assistance) were assessed using items from the Add-Health Study, ${ }^{41,42}$ the NIH Guidelines on race/ethnicity, ${ }^{43}$ and the Drug Abuse Treatment Outcome Studies. ${ }^{44}$ Three items from the Flint Adolescent Survey ${ }^{45}$ assessed school completion ("Are you currently in school?"; "What is the highest grade you have completed?") and average grades ("What kind of grades do you usually/did you usually get in school?"). Participants who reported that they were not currently in school and who indicated that the highest grade completed was less than a high school diploma were coded as dropouts. Education measures were collapsed to indicate whether the participant had failing grades or had dropped out of school.

Past 2-month Background Characteristics. Firearm carriage was assessed using a single item ("How often have you carried a gun with you when you were outside your home?") from the Tulane Youth Study. ${ }^{46,47}$ The response scale (never, one time, two times, three to five times, six to 10 times, 11 to 20 times, $>20$ times) was dichotomized (yes/no for firearm carriage) for analysis. This measure excludes firearm carriage for hunting/ sporting activities. Gang involvement was assessed with a single item (Do you consider yourself a member of a gang?; yes/no). ${ }^{26,48}$ Community violence exposure was assessed with the five-item community violence scale from the "Things I Have Seen and Heard Survey." ${ }^{\prime 4,50}$ This scale assesses the frequency of five behaviors ("heard gun shots"; "seen drug deals"; "my house has been broken into"; "seen someone get stabbed or shot"; "seen gangs in my neighborhood") on a Likert scale ranging from 0 ("never") to 3 ("many times"). For analysis, a summary score was created (range $0-15 ; \alpha=0.72$ ), with higher scores indicative of higher perceived levels of community violence exposure.

Alcohol ("In the past 2 months, have you had a drink of beer, wine, or liquor more than 2-3 times"; yes/no) and marijuana use ("During the past 2 months, how many days did you use marijuana?") were assessed using measures from the Add-Health Survey. ${ }^{42}$ For analysis, any response other than never to the marijuana item (response scale-never, $<1$ time a month, 2-3 days/month; 1-2 days/week; 3-5 days/week; every day) was coded as positive for recent marijuana use (yes/no). Finally, participants were asked to indicate whether this ED visit resulted from a violent injury (yes/ no).

Primary Outcomes. The main outcomes for the study were physical aggression, victimization, and self-efficacy for nonfighting. The adapted 12-item revised conflict tactics scale (CTS-2) ${ }^{51,52}$ and the 4 -item conflict in adolescent dating relationships inventory (CADRI) ${ }^{53}$ were used to measure prevalence and frequency of physical aggression and victimization for peers (e.g., friends, strangers, acquaintances, relatives) and partners (e.g., girlfriend/boyfriend, fiancée, husband/wife), respectively. Each scale measures the frequency (response scale ranging from 0 [never] to six [ $>20$ times]) of moderate (e.g., pushed, shoved) and severe (e.g., hit, punched, used a knife/gun) violence behaviors and are measured separately for victimization (i.e., someone did to you) and aggression (i.e., you did to someone). Peer and partner scores were summed for a total measure of physical aggression $(\alpha=0.90)$ and physical victimization $(\alpha=0.92)$. Self-efficacy for avoiding fighting was assessed using a five-item scale (How sure are you that you can "stay out of fights?"; "Understand another person's point of view?"; "Calm down when you are mad?"; "talk out a disagreement?"; "Learn to say out of fights?") from the Teen Conflict Survey; ${ }^{54,55}$ responses ranged from 0 (not at all) to 4 (extremely) and were summed for a total self-efficacy score (range 0-20; $\alpha=0.80$ ).

\section{Study Conditions}

Brief Intervention. Youth in the intervention group received the $\sim 30$-minute therapist-delivered BI within the ED prior to hospital admission/discharge. The study therapist was aided by a tablet computer to provide both tailored feedback to the participant and to standardize the delivery of intervention content. The BI was paused and restarted as necessary to avoid interfering with medical care. The Project Sync BI integrated elements of motivational interviewing (MI) to enhance 
problem recognition (i.e., why behaviors negatively influence goals) with cognitive behavioral strategies for skill development (i.e., how to change current behaviors). MI is a person-centered counseling technique emphasizing a nonjudgmental and nonconfrontational approach. ${ }^{56,57}$ MI focuses on establishing a discrepancy between current behaviors and future goals to resolve ambivalence, enhance intrinsic motivation, and increase self-efficacy for change. The intervention proceeded through five sections: 1) reviewing personalized goals; 2) delivering tailored feedback on violence (including normative re-setting and how substance use contributes to behaviors); 3) decisional balance exercises to establish the potential benefits of avoiding fighting (e.g., preventing injury); 4) five role-playing scenarios to develop cognitive skills in anger management, conflict resolution, refusal skills for substance use/weapon carriage, and skills for avoiding violent situations; and 5) summary of goals, skills discussed, and linkage to community resources. A detailed community resource brochure was also provided.

The Project Sync BI was adapted from the previously described SafERteens BI, ${ }^{36-38}$ which was designed specifically for teens with prior alcohol use and fighting. Modifications included adapting the role-playing scenarios and intervention content to be applicable to youth regardless of their history of prior violence or prior alcohol use (i.e., relevant for a universal ED sample). If youth had not experienced fighting, the therapist focused on the prevention of future aggression and victimization and/or discussed situations that the participant's friends, family, or neighbors had experienced. In addition, intervention scenarios were updated to be reflective of more current teen issues than those used in the SafERteens study (e.g., "someone stole your cellphone" rather than "someone stole your sneakers"). As with SafERteens, intervention content was developed to be culturally relevant for urban youth.

The Project Sync BI was delivered by study therapists trained in behavioral health fields (e.g., social work, clinical psychology). They completed a 5-day training at the beginning of the study, including training in MI techniques and intervention delivery. Prior to study initiation, therapists completed mock patient scenarios and were required to demonstrate appropriate proficiency with MI and all components of intervention delivery. In addition, study therapists were carefully monitored throughout the trial in four ways. First, they received close clinical supervision and review of audiotaped therapy sessions by a licensed therapist during the initial weeks of the study as a quality assurance check. Second, study therapists were required to complete individual regular clinical supervision twice a month and group clinical supervision once a month with a licensed therapist throughout the study to ensure adherence to all aspects of the study protocol. Third, study therapists received booster trainings throughout the study (twice/year) to maintain clinical skills and prevent drift from the study protocol. Finally, a random $5 \%$ of all therapy sessions were audiotaped and coded using the Motivational Interviewing Treatment Integrity Global Scale (MITI-3), ${ }^{58}$ a standardized instrument for measuring and ensuring that the therapist is adhering to the principles of MI and the therapy protocol in clinical trials that involve MI-based behavioral counseling. For this study, therapy sessions demonstrated acceptable fidelity (mean \pm SD global spirit rating $=4.8 \pm 0.3$; range $=3.7-5.0]$ ), exceeding the recognized competency level of 4 .

Enhanced Usual Care. Participants in the EUC condition received a basic brochure listing available community resources (e.g., substance use, leisure activities).

\section{Data Analysis}

Descriptive statistics were computed for the entire sample and by assigned treatment condition. Frequencies of risk behaviors (e.g., violent victimization, aggression, self-efficacy) were computed for descriptive purposes and percent change at 2 months following the ED visit are presented. Regression analyses (i.e., Poisson based on distribution) were conducted examining the effects of the BI (compared to EUC) on the occurrence (binary variable) and frequency (continuous) of primary outcomes (i.e., aggression, victimization, self-efficacy). For victimization and aggression, zero-inflated Poisson (ZIP) models were utilized to account for the large proportion of zeros. Follow-up rates were high $(91.2 \%)$ and attrition analyses demonstrated that baseline characteristics (i.e., age, race, sex, assigned group) were not significantly related to follow-up, suggesting that missing outcome data were likely missing at random. Cohen effect sizes $^{59}$ were calculated to indicate the strength of the relationship between the BI and observed outcomes to allow for future comparison. Prior prevention literature suggests that effect sizes $>0.10$ are clinically meaningful. ${ }^{60}$ Data were analyzed using SAS 9.4 (SAS Institute Inc.).

\section{RESULTS}

\section{Enrollment}

A total of 1,188 patients aged 14 to 20 years old with a home address within the intervention or comparison neighborhood presented during recruitment (Figure 1). Of 619 youth eligible for inclusion, 80.5\% $(n=498)$ were approached, with $82.1 \% \quad(409 ; \quad \mathrm{BI}=263 ; \quad \mathrm{EUC}=146)$ enrolling in the study and $17.9 \%(n=89)$ refusing participation. Those refusing participation were more likely from the intervention rather than the comparison neighborhood $\left(21.7 \%\right.$ vs. $9.9 \%, \chi^{2}=10.46$; $\left.p<0.05\right)$ and were less likely to identify as African American when compared with other racial/ethnic categories $(16.6 \%$ vs. $\left.32.5 \%, \chi^{2}=6.34 ; \mathrm{p}<0.05\right)$. No differences were noted with regards to age or sex. Compliance with assigned condition and follow-up rates exceeded $91.2 \%$, with no differential follow-up by condition. Of note, only five participants $(1.9 \%)$ in the intervention group reported exposure to one of the other youth violence initiatives, with four of the five reporting their exposure was to a community-level clean and greening initiative. The remaining 98\% reported no direct exposure to the other YVPC community interventions.

\section{Participant Characteristics}

Table 1 characterizes the sample by study condition. No differences between groups were noted by condition 


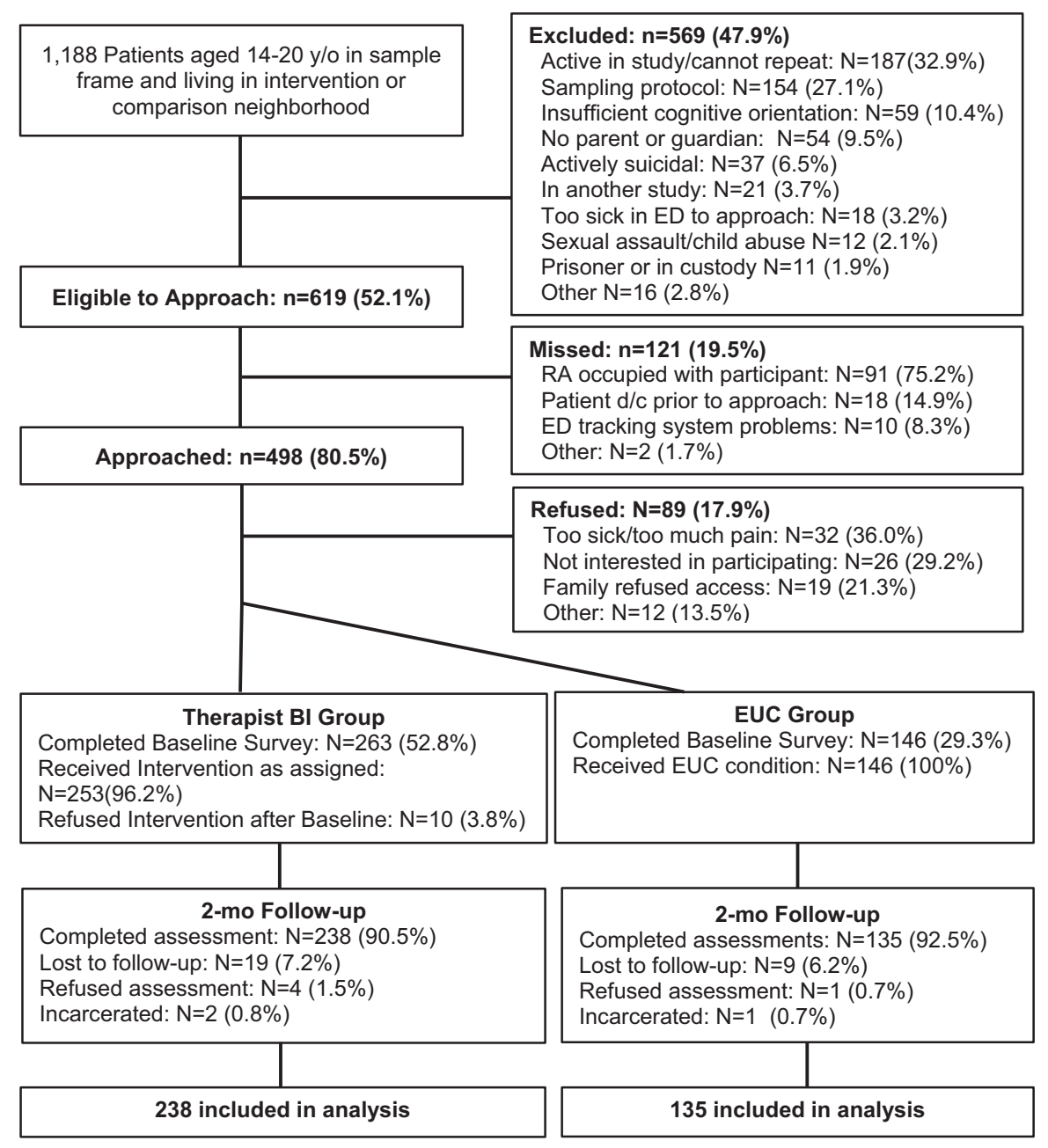

Figure 1. Project Sync flow chart for recruitment and study enrollment from Hurley Medical Center in Flint, Michigan (October 4, 2011-March 30, 2015). BI = brief intervention.

with regard to background characteristics, substance use, and/or violence involvement. Among the entire sample, $59.9 \%$ of participants were female, $93.4 \%$ were African American, and mean $( \pm$ SD) age was $17.7( \pm 1.9)$ years. Most participants in both groups reported receipt of some public assistance $(79.0 \%)$ and $75.3 \%$ reported living with a parent/guardian. Overall, $20.1 \%$ of youth reported recent alcohol use and $38.6 \%$ reported recent marijuana use. Recent violence involvement was similar between conditions, with two-thirds of youth reporting a recent violent event; $48.2 \%$ reported being the aggressor and $58.7 \%$ reported being victimized. Among all participants, only $8.8 \%$ were seeking care for a violent injury.

\section{Primary Outcomes}

Overall, $85.7 \%(n=209)$ of participants receiving the intervention rated the BI as very or extremely helpful (mean \pm SD score $=3.3 \pm 0.8$ ). Regression models computed for violence outcomes (aggression, victimization, and self-efficacy for avoiding fighting) at 2 months (Table 2, descriptive data; Table 3, Poisson/ZIP models) demonstrated that the BI significantly decreased the frequency of violent aggression (BI, -46.8\%; EUC,
$-36.9 \%$; incident rate ratio $[\mathrm{IRR}]=0.87 ; 95 \% \mathrm{CI}=0.76$ 0.99) and increased self-efficacy for avoiding fighting (BI, $+7.2 \%$; EUC, $-1.3 \%$; IRR $=1.09 ; 95 \%$ CI $=1.02-1.15)$ when compared to EUC. No significant changes were noted for frequency of victimization or for the prevalence of victimization or aggression. Cohen's d effect sizes for the BI were as follows: violent aggression, 0.16 ; and self-efficacy, 0.24 .

\section{DISCUSSION}

Results demonstrate that a 30-minute BI was effective at reducing violent aggression and increasing self-efficacy for avoiding fighting among a universal sample of youth seeking ED care in a high-risk community. Although effect sizes were modest, findings are similar to other ED-based behavioral ${ }^{35,61}$ and school-based universal violence interventions. ${ }^{62}$ Further, effect sizes are clinically significant given that violent injury is the leading cause of death among urban youth, surpassing death due to cancer, asthma, HIV/AIDS, and motor vehicle collision injury. ${ }^{63}$ In addition, these findings further validate the findings of the SafERteens study, demonstrating that a BI delivered during an ED visit can be 
Table 1

Baseline Background, Violence, and Substance Use Characteristics by Study Condition

\begin{tabular}{|c|c|c|c|}
\hline & $\begin{array}{l}\text { Therapist BI } \\
\text { Group } \\
(n=263)\end{array}$ & $\begin{array}{l}\text { EUC Group } \\
(n=146)\end{array}$ & $\begin{array}{c}\text { Total } \\
(n=409)\end{array}$ \\
\hline \multicolumn{4}{|c|}{ Background characteristics } \\
\hline Age $(y)$ & $17.7( \pm 1.9)$ & $17.5( \pm 2.0)$ & $17.7( \pm 1.9)$ \\
\hline Female & $161(61.2)$ & $84(57.5)$ & $245(59.9)$ \\
\hline $\begin{array}{l}\text { African } \\
\text { American }\end{array}$ & $243(92.4)$ & $139(95.2)$ & $382(93.4)$ \\
\hline $\begin{array}{l}\text { Married/living } \\
\text { with partner }\end{array}$ & $43(16.4)$ & $26(17.8)$ & $69(16.9)$ \\
\hline $\begin{array}{l}\text { Live with } \\
\text { parent/ } \\
\text { guardian }\end{array}$ & $191(72.6)$ & $117(80.1)$ & $308(75.3)$ \\
\hline $\begin{array}{l}\text { Public } \\
\text { assistance } \\
\text { (parent or } \\
\text { participant) }\end{array}$ & 209 (79.5) & $114(78.1)$ & $323(79.0)$ \\
\hline $\begin{array}{l}\text { Failing } \\
\text { grades/ } \\
\text { dropped out } \\
\text { of school }\end{array}$ & $60(22.8)$ & $30(20.6)$ & $90(22.0)$ \\
\hline $\begin{array}{l}\text { Gang } \\
\text { involvement }\end{array}$ & $17(6.5)$ & $6(4.1)$ & $23(5.6)$ \\
\hline $\begin{array}{l}\text { Firearm } \\
\text { carriage }\end{array}$ & $23(8.7)$ & $12(8.2)$ & $35(8.6)$ \\
\hline $\begin{array}{l}\text { Community } \\
\text { violence }\end{array}$ & $5.2( \pm 3.4)$ & $5.4( \pm 3.4)$ & $5.3( \pm 3.4)$ \\
\hline \multicolumn{4}{|l|}{ ED visit/presentation } \\
\hline $\begin{array}{l}\text { Violent } \\
\text { injury }\end{array}$ & $19(7.2)$ & $17(11.6)$ & $36(8.8)$ \\
\hline \multicolumn{4}{|c|}{ Past 2-month substance use } \\
\hline $\begin{array}{l}\text { Any alcohol } \\
\text { use }\end{array}$ & $51(19.4)$ & $31(21.2)$ & $82(20.1)$ \\
\hline $\begin{array}{l}\text { Any marijuana } \\
\text { use }\end{array}$ & $100(38.0)$ & $58(39.7)$ & $158(38.6)$ \\
\hline \multicolumn{4}{|c|}{ Past 2-month violence experiences } \\
\hline $\begin{array}{l}\text { Any experiences } \\
\text { of violence }\end{array}$ & $173(65.8)$ & $90(61.6)$ & $263(64.3)$ \\
\hline $\begin{array}{l}\text { Any violent } \\
\text { aggression }\end{array}$ & $128(48.7)$ & $69(47.3)$ & $197(48.2)$ \\
\hline $\begin{array}{l}\text { Any violent } \\
\text { victimization }\end{array}$ & $162(61.6)$ & $78(53.4)$ & $240(58.7)$ \\
\hline $\begin{array}{l}\text { Self-efficacy } \\
\text { for avoiding } \\
\text { fights }\end{array}$ & $12.9( \pm 4.4)$ & $13.1( \pm 4.6)$ & $13.0( \pm 4.5)$ \\
\hline \multicolumn{4}{|c|}{$\begin{array}{l}\text { Data are reported as mean }( \pm S D) \text { or } n(\%) . \text { Significance } \\
\text { levels: } * p<0.05, * * p<0.01, * * *<0.001 . \\
\mathrm{BI}=\text { brief intervention; EUC }=\text { enhanced usual care. }\end{array}$} \\
\hline
\end{tabular}

efficacious in reducing adolescent violent behaviors. ${ }^{37,61}$ Our study adds to the literature by demonstrating that components of the SafERteens BI can be successfully adapted for application among a universal sample that is not being screened for alcohol use or prior violence. We found that the universal intervention was well received by participants, with low refusal rates $(<20 \%)$ and with $86 \%$ of youth rating the intervention as very or extremely helpful, reinforcing that youth in high-risk neighborhoods, even those youth without prior violence history, are willing to discuss ways to reduce their future violence risk. Taken together, these findings have important public health implications for communities with elevated levels of violence, as the ED is a critical site for reaching youth who do not attend school $(22 \%$
Table 2

Within-condition (Therapist BI Group; EUC Group) Self-report of Changes in Violent Victimization, Aggression, and Self-efficacy for Nonviolence at Baseline to the 2-month Follow-up

\begin{tabular}{|c|c|c|c|}
\hline & Baseline & $\begin{array}{l}\text { 2-Month } \\
\text { Follow-Up }\end{array}$ & $\begin{array}{c}\text { Change From } \\
\text { Baseline to } \\
2 \text { months, } \\
\% \text { Change }\end{array}$ \\
\hline \multicolumn{4}{|c|}{ Any violent victimization } \\
\hline $\begin{array}{l}\text { Therapist } \\
\text { BI group }\end{array}$ & $6.07( \pm 11.55)$ & $2.93( \pm 6.60)$ & $-51.7 \% * * *$ \\
\hline EUC group & $4.37( \pm 7.20)$ & $2.50( \pm 5.64)$ & $-42.8 \%$ \\
\hline \multicolumn{4}{|c|}{ Any violent aggression } \\
\hline $\begin{array}{l}\text { Therapist } \\
\text { BI group }\end{array}$ & $4.81( \pm 9.05)$ & $2.56( \pm 6.06)$ & $-46.8 \% * * *$ \\
\hline EUC group & $3.96( \pm 6.88)$ & $2.50( \pm 6.04)$ & $-36.9 \% * * *$ \\
\hline \multicolumn{4}{|c|}{ Self-efficacy for avoiding fighting } \\
\hline $\begin{array}{c}\text { Therapist } \\
\text { Bl group }\end{array}$ & $12.87( \pm 4.39)$ & $13.79( \pm 4.64)$ & $+7.2 \% * * *$ \\
\hline EUC group & $13.10( \pm 4.60)$ & $12.93( \pm 5.22)$ & $-1.3 \%$ \\
\hline \multicolumn{4}{|c|}{$\begin{array}{l}\text { Data are reported as means }( \pm S D) \text {. Significance levels: } \\
* \mathrm{p}<0.05, * * \mathrm{p}<0.01, * * * \mathrm{p}<0.001 . \\
\mathrm{BI}=\text { brief intervention; } \mathrm{EUC}=\text { enhanced usual care. }\end{array}$} \\
\hline
\end{tabular}

Table 3

ZIP Regression Analyses Examining the Efficacy of the Therapist BI (vs. the EUC Group) on the Extent of Violence Victimization, Aggression and Self-efficacy at the 2-Month Follow-up

\begin{tabular}{|c|c|c|}
\hline & $\begin{array}{l}\text { IRR* }(95 \% \mathrm{Cl}) \\
\text { Frequency }\end{array}$ & $\begin{array}{l}\text { AOR }(95 \% \mathrm{Cl}) \\
\text { Prevalence }\end{array}$ \\
\hline \multicolumn{3}{|c|}{ Any violent victimization } \\
\hline $\begin{array}{l}\text { Baseline } \\
\text { victimization }\end{array}$ & $1.02(1.02-1.03)^{* * *}$ & $0.87(0.83-0.91)^{* * *}$ \\
\hline Therapist BI & $1.02(0.89-1.16)$ & $1.06(0.66-1.70)$ \\
\hline \multicolumn{3}{|c|}{ Any violent aggression } \\
\hline $\begin{array}{l}\text { Baseline } \\
\text { aggression }\end{array}$ & $1.04(1.03-1.04)^{* * *}$ & $0.91(0.88-0.94)^{* * *}$ \\
\hline Therapist BI & $0.87(0.76-0.99)^{*}$ & $0.78(0.49-1.24)$ \\
\hline \multicolumn{3}{|c|}{ Self-efficacy for avoiding fighting $\dagger$} \\
\hline $\begin{array}{l}\text { Baseline } \\
\text { self-efficacy }\end{array}$ & $1.05(1.04-1.05)^{* * *}$ & - \\
\hline Therapist BI & $1.09(1.02-1.15)^{* *}$ & - \\
\hline \multicolumn{3}{|c|}{$\begin{array}{l}\text { Significance levels: } * \mathrm{p}<0.05, * * \mathrm{p}<0.01, * * * \mathrm{p}<0.001 . \\
\mathrm{AOR}=\text { adjusted odds ratio; BI = brief intervention; EUC = en- } \\
\text { hanced usual care; IRR = incident rate ratio; ZIP = zero- } \\
\text { inflated Poisson. } \\
* \text { IRR values }>1 \text { indicate variables associated positively with } \\
\text { the outcome of interest and values }<1.0 \text { indicate variables } \\
\text { associated negatively with the outcome of interest. } \\
\dagger \text { Self-efficacy for avoiding fighting was a Poisson regression } \\
\text { model. }\end{array}$} \\
\hline
\end{tabular}

in our sample) or receive regular primary care, and may represent a promising primary prevention tool for reducing violence in such communities.

Improved violence outcomes may have resulted from a combined focus on increasing motivation for behavior change and increasing their skills for avoiding violent situations, nonviolent conflict resolution, and anger management. Alternatively, intervention effects may have resulted from the focus on social promotive factors, including linkage to available psychosocial or 
substance use resources and to positive community activities. Further study is needed to identify which intervention components were critical to the effectiveness of the BI among this universal sample. Understanding which components were the most effective will aid in the design and implementation of future violence interventions. It should be noted that aggression behaviors included moderate and severe behaviors (e.g., knife/firearm use). Due to the limited sample size, it is unknown whether youth with higher severity violence profiles were more motivated to change their behavior. More study with a larger adolescent sample is needed to understand the mediating and moderating factors that may have influenced outcomes.

Although additional study is needed to assess the generalizability of our findings, the combined approach of focusing on individual-level therapist-delivered behavioral counseling and cognitive skill development among a universal population of at-risk adolescents has the potential to be effective in other clinical and nonclinical settings. Universal school-based violence interventions have shown efficacy addressing a range of violence-related behaviors among school-aged populations. ${ }^{64}$ Yet, most studies to date have focused on positive youth development among younger elementary and middle school-aged children. Further, among studies focused on high school-aged adolescents, most are limited to educational programs or peer-based mentoring for bullying and/or dating violence behaviors. ${ }^{64}$ Within pediatric primary care settings, several screening tools for violence risk have been developed, ${ }^{65-67}$ but few researchers have examined the best methods of intervening with adolescents who screen positive for violence risk and/or those who are at risk as a result of living in high-risk communities. ${ }^{68}$ In addition, few researchers have examined a therapist-delivered $\mathrm{BI}$ to address a broader range of violence behaviors in school or primary care settings. Such an approach may be an effective universal prevention tool for addressing violence risk among adolescent populations in these settings, although further study is needed.

We did not observe a decrease in victimization during follow-up. This finding, which differs from the SafERteens study, may have resulted from our focus on a universal sample. Less than $65 \%$ of our youth reported violent experiences (aggression or victimization) in the 2 months preceding their ED visit. In contrast, recent fighting and alcohol use were inclusion criteria for the SafERteens study, and more than $80 \%$ of that sample reported experiencing consequences (e.g., trouble at school) due to their violence involvement. ${ }^{61}$ Prior violence may serve to differentially enhance the salience of intervention components related to victimization, including such cognitive elements as developing skills for avoiding violence. Alternatively, the shorter follow-up period for our study may have limited participant exposure to violence situations, reducing the opportunity to observe changes in victimization. Further study and a longer follow-up period are needed to fully understand the effects of the Project Sync BI on victimization.

While a computerized workbook was used to guide the $\mathrm{BI}$ and increase fidelity, it is important to note that an on- site, in-person therapist was required. This approach has implications for translating and disseminating the Project Sync BI into busy, understaffed urban EDs, as well as for the cost-effectiveness of this BI as a universal prevention tool. Prior evaluations testing a fully computerized version of the SafERteens BI did not demonstrate efficacy for violence, but did reduce alcohol-related consequences. ${ }^{61,69}$ Similarly, a recent study demonstrated that a fully automated stand-alone computer BI was effective in reducing alcohol consumption and alcohol related consequences (e.g., DUI) among underage risky drinkers. ${ }^{35}$ It may be that key components of violence BIs, including empathy or complex therapist reflections concerning youth involvement in violence, may not be easily transferred to a computerized platform. Alternatively, recently tested BIs with efficacy reducing substance use may have benefited from advancements in automated tailoring technology. In addition, the marked increase in adolescent utilization of interactive technologies such as social media may serve to enhance the effectiveness of newer technology-based therapeutic interventions. Regardless, further study is needed to develop the most seamless and cost-effective delivery method for a universal violence BI. One potential alternative is the use of centralized call centers with access to remote therapists that can deliver the intervention, especially among lowresource urban EDs. This approach has recently gained acceptance in medical and research communities, as well as among large insurance agencies for other disease management and behavioral interventions, ${ }^{70-74}$ and may offer a more cost-efficient delivery method for underserved low-resource settings.

\section{LIMITATIONS}

Study limitations should be acknowledged, including the quasi-experimental rather than RCT design. This concern is partly mitigated by the absence of baseline differences among study conditions and the focus of the study on replicating the positive SafERteens effects among a universal sample. However, it must be acknowledged that we cannot fully account for the full range of potential unmeasured confounding variables with this design. Findings may not generalize to youth not included in the study, including those in Flint who do not reside in the intervention or comparison neighborhoods, as well as those who were excluded (e.g., youth seeking care for suicidal ideation/sexual assault). While the sample reflected the racial and ethnic composition of the study site, further testing among youth with other racial and ethnic characteristics (e.g., Hispanic) is required. The use of self-report data is a potential limitation; however, prior studies confirm the reliability and validity of self-report data when privacy and confidentiality are assured. ${ }^{75}$ Although attrition is a potential limitation, follow-up rates exceeded 90\%. Further study with a longer follow-up period is required to assess the effects of the BI on long-term outcomes. Finally, as this was one component of a larger youth violence prevention program, there may have been spillover effects from the other interventions; however, less than $2 \%$ of the intervention group reported exposure to one of the other youth violence initiatives. 


\section{CONCLUSION}

Our evaluation suggests that a universal brief intervention for violence, delivered by a therapist in the ED setting, can be effective in reducing aggression and increasing self-efficacy for avoiding fighting among a universal sample of youth in a high-risk community. These findings have important implications for community-based violence prevention programs addressing this complex public health problem. Future research should focus on investigating alternative cost-efficient delivery mechanisms that can improve the likelihood of translating this universal brief intervention into the routine clinical care that is provided to ED youth in high-risk communities to decrease the leading cause of morbidity and mortality among urban youth.

The authors acknowledge project staff including Aaron Cheek, LLBSW, and Sandra Evans, LLMSW, for their work on this project, Wendi Mohl, BS, for her assistance in manuscript preparation; and Linping Duan, MS, for her assistance with statistical analysis. Finally, special thanks are owed to the patients and medical staff of the Hurley Medical Center (HMC) and the Michigan Youth Violence Prevention Center (YVPC) Steering Committee for their support of this project.

\section{References}

1. Grinshteyn E, Hemenway D. Violent death rates: the United States compared to other high-income OECD countries, 2010. Am J Med 2016;129:266-73.

2. Centers for Disease Control and Prevention. Webbased Injury Statistics Query and Reporting System. 2014. Available from: http://www.cdc.gov/injury/ wisqars/. Accessed Oct 29, 2015.

3. Kann L, Kinchen S, Shanklin SL, et al. Youth risk behavior surveillance-United States, 2013. MMWR Surveill Summ 2014;63(Suppl 4):1-168.

4. Corso PS, Mercy JA, Simon TR, Finkelstein EA, Miller TR. Medical costs and productivity losses due to interpersonal and self-directed violence in the United States. Am J Prev Med 2007;32:474-82.

5. Cunningham R, Knox L, Fein J, et al. Before and after the trauma bay: the prevention of violent injury among youth. Ann Emerg Med 2009;53:490-500.

6. NIH State-of-the-Science Statement on Preventing Violence and Related Health-Risking Social Behaviors in Adolescents. Bethesda, MD: National Institutes of Health; 2004.

7. Committee on Injury Violence. Policy statement-role of the pediatrician in youth violence prevention. Pediatrics 2009;124:393.

8. Muelleman RL, Reuwer J, Sanson TG, et al. An emergency medicine approach to violence throughout the life cycle. SAEM Public Health and Education Committee. Acad Emerg Med 1996;3:708-15.

9. Fein JA, Ginsburg KR, McGrath ME, Shofer FS, Flamma JC, Datner EM. Violence prevention in the emergency department. Arch Pediatr Adolesc Med 2000;154:495.

10. National Research Council and Institute of Medicine. Injury in America: A Continuing Health Problem. Washington, DC: National Academy Press, 1985.
11. National Prevention Council. National Prevention Strategy: Injury and Violence Free Living. Rockville, MD: Office of the Surgeon General, 2011.

12. Gorman-Smith D, Henry DB, Tolan PH. Exposure to community violence and violence perpetration: the protective effects of family functioning. J Clin Child Adolesc Psychol 2004;33:439-49.

13. Walton MA, Cunningham RM, Chermack ST, Maio $\mathrm{R}$, Blow FC, Weber J. Correlates of violence history among injured patients in an urban emergency department: gender, substance use, and depression. J Addict Dis 2007;26:61-75.

14. Cunningham RM, Ranney M, Newton M, Woodhull W, Zimmerman M, Walton MA. Characteristics of youth seeking emergency care for assault injuries. Pediatrics 2014;133:e96-e105.

15. Zatzick D, Jurkovich G, Rivara FP, et al. A randomized stepped care intervention trial targeting posttraumatic stress disorder for surgically hospitalized injury survivors. Ann Surg 2013;257:390-9.

16. Margolin G, Vickerman KA, Oliver PH, Gordis EB. Violence exposure in multiple interpersonal domains: cumulative and differential effects. J Adolesc Health 2010;47:198-205.

17. Boynton-Jarrett R, Ryan LM, Berkman LF, Wright RJ. Cumulative violence exposure and self-rated health: longitudinal study of adolescents in the United States. Pediatrics 2008;122:961-70.

18. Taylor TJ, Freng A, Esbensen FA, Peterson D. Youth gang membership and serious violent victimization: the importance of lifestyles and routine activities. J Interpers Violence 2008;23:1441-64.

19. Cunningham RM, Carter PM, Ranney M, et al. Violent reinjury and mortality among youth seeking emergency department care for assault-related injury. JAMA Pediatr 2015;169:63.

20. Carter PM, Walton MA, Roehler DR, et al. Firearm violence among high-risk emergency department youth after an assault injury. Pediatrics 2015;135: 805-15.

21. Stoddard SA, Whiteside L, Zimmerman MA, Cunningham RM, Chermack ST, Walton MA. The relationship between cumulative risk and promotive factors and violent behavior among urban adolescents. Am J Commun Psychol 2012;51:57-65.

22. Pailler ME, Kassam-Adams N, Datner EM, Fein JA. Depression, acute stress and behavioral risk factors in violently injured adolescents. Gen Hosp Psychiatry 2007;29:357-63.

23. Cunningham $R$, Walton $M$, Trowbridge $M$, Weber J, Outman R, Benway A, Maio R. Correlates of violent behavior among adolescents presenting to an urban emergency department. J Pediatr 2006;149:770-6.

24. Walton MA, Cunningham RM, Goldstein AL, et al. Rates and correlates of violent behaviors among adolescents treated in an urban emergency department. J Adolesc Health 2009;45:77-83.

25. Carter PM, Walton MA, Newton MF, et al. Firearm possession among adolescents presenting to an urban emergency department for assault. Pediatrics 2013;132:213-21. 
26. Zun LS, Downey L, Rosen J. Who are the young victims of violence? Pediatr Emerg Care 2005;21:568-73.

27. Ramirez M, Wu Y, Kataoka S, Wong M, Yang J, Peek-Asa C, Stein B. Youth violence across multiple dimensions: a study of violence, absenteeism, and suspensions among middle school children. J Pediatr 2012;161:542-46.e2.

28. Grove DD, Lazebnik R, Petrack EM. Urban emergency department utilization by adolescents. Clin Pediatr (Phila) 2000;39:479-83.

29. Johnston BD, Rivara FP, Droesch RM, Dunn C, Copass MK. Behavior change counseling in the emergency department to reduce injury risk: a randomized, controlled trial. Pediatrics 2002;110(2 Pt 1):267-74.

30. Monti PM, Colby SM, Barnett NP, et al. Brief intervention for harm reduction with alcohol-positive older adolescents in a hospital emergency department. J Consult Clin Psychol 1999;67:989-94.

31. Gregor MA, Shope JT, Blow FC, Maio RF, Weber JE, Nypaver MM. Feasibility of using an interactive laptop program in the emergency department to prevent alcohol misuse among adolescents. Ann Emerg Med 2003;42:276-84.

32. Spirito A, Monti PM, Barnett NP, et al. A randomized clinical trial of a brief motivational intervention for alcohol-positive adolescents treated in an emergency department. J Pediatr 2004;145:396-402.

33. Strecher V, Wang C, Derry H, Wildenhaus K, Johnson C. Tailored interventions for multiple risk behaviors. Health Educ Res 2002;17:619-626.

34. Bernstein E, Bernstein J, Levenson S. Project ASSERT: an ED-based intervention to increase access to primary care, preventive services, and the substance abuse treatment system. Ann Emerg Med 1997;30:181-9.

35. Cunningham RM, Chermack ST, Ehrlich PF, et al. Alcohol interventions among underage drinkers in the ED: a randomized controlled trial. Pediatrics 2015;136:e783-93.

36. Walton MA, Chermack ST, Shope JT, et al. Effects of a brief intervention for reducing violence and alcohol misuse among adolescents: a randomized controlled trial. JAMA 2010;304:527-35.

37. Cunningham RM, Chermack S, Zimmerman MA, et al. Brief motivational interviewing intervention for peer violence and alcohol use in teens: one year follow-up. Pediatrics 2012;129:1083-90.

38. Cunningham RM, Whiteside LK, Chermack ST, et al. Dating violence: outcomes following a brief motivational interviewing intervention among atrisk adolescents in an urban emergency department. Acad Emerg Med 2013;20:562-9.

39. Uniform Crime Reports: Table 8 - Offenses Known to Law Enforcement by State by City. Washington, DC: Federal Bureau of Investigation, 2013.

40. Heinze JE, Reischl TM, Bai M, et al. A comprehensive prevention approach to reducing assault offenses and assault injuries among youth. Prev Sci 2015;17:167-76.

41. Harris K, Florey F, Tabor J, Bearman P, Jones J, Udry J. The National Longitudinal Study of Adolescent to Adult Health: Study Design. 2003. Available at: http://www.cpc.unc.edu/projects/addhealth/design. Accessed May 21, 2008.

42. Bearman PS, Jones J, Udry JR. The National Longitudinal Study of Adolescent to Adult Health: Research Design. 1997. Available at: http://www.cpc.unc.edu/ projects/addhealth. Accessed May 21, 2005.

43. NIH Policy on Reporting Race and Ethnicity Data: Subjects in Clinical Research. Bethesda, MD: National Institues of Health, 2001.

44. U.S. National Institute on Drug Abuse. Drug Abuse Treatment Outcome Study (DATOS). Washington, DC: Department of Health and Human Services; ed1991-1995.

45. Zimmerman M. Flint [Michigan] Adolescent Study (FAS): A Longitudinal Study of School Dropout and Substance Use, 1994-1997. Ann Arbor, MI; University of Michigan, 2014.

46. Sheley JF, Wright JD. Tulane University National Youth Study. New Orleans, LA: Tulane University, 1995.

47. Sheley JF, Wright JD. High School Youth, Weapons, and Violence: A National Survey of WeaponRelated Experiences, Behaviors, and Concerns. PsycEXTRA Dataset. Washington, DC: American Psychological Association (APA), 1998.

48. Henry DB, Tolan PH, Gorman-Smith D. Longitudinal family and peer group effects on violence and nonviolent delinquency. J Clin Child Psychol 2001;30:172-86.

49. Richters JE, Saltzman W. Survey of exposure to violence: Self report version. Rockville, MD: National Institute of Mental Health,1990.

50. Richters JE, Martinez P. Things I Have Seen and Heard: A Structured Interview for Assessing Young Children's Violence Exposure. Rockville, MD: National Institute of Mental Health, 1990.

51. Straus MA. Conflict Tactics Scales. In: Jackson NA, editor. Encyclopedia of Domestic Violence. New York: Routledge: Taylor \& Francis Group, 2007. p. 824.

52. Straus MA, Hamby SL, Boney-McCoy S, Sugarman DB. The Revised Conflict Tactics Scales (CTS2) development and preliminary psychometric data. J Fam Issues 1996;17:283-316.

53. Wolfe DA, Scott K, Reitzel-Jaffe D, Wekerle C, Grasley C, Straatman AL. Development and validation of the conflict in adolescent dating relationships inventory. Psychol Assess 2001;13:277-93.

54. Bosworth K, Espelage D. Teen Conflict Survey. Bloomington, IN: Center for Adolescent Studies, Indiana University, 1995.

55. Dahlberg LL, Toal SB, Behrens CB. Measuring violence-related attitudes, beliefs, and behaviors among youths: a compendium of assessment tools. Atlanta, GA: Division of Violence Prevention, National Center for Injury Prevention and Control, Centers for Disease Control and Prevention, 1998.

56. Rollnick S, Miller W, Butler C. Motivational Interviewing in Health Care: Helping Patients Change Behavior. New York: Guilford, 2007.

57. Resnicow K, Rollnick S. Motivational Interviewing in Health Promotion and Behavioral Medicine. Handbook of Motivational Counseling: Goal-based 
Approaches to Assessment and Intervention with Addiction and Other Problems. Hoboken, NJ: John Wiley \& Sons, Ltd, 2004.

58. Moyers T, Martin T, Manuel J, Miller W, Ernst D. Revised Global Scales: Motivational Interviewing Treatment Integrity 3.0 (MITI 3.0). Albuquerque, NM: University of New Mexico, Center on Alcoholism, Substance Abuse and Addictions (CASAA), 2007. p. 28.

59. Hedges LV, Olkin I. Statistical Methods for Metaanalysis. San Diego, CA: Academic Press, 1985.

60. Gottfredson DC, Wilson DB. Characteristics of effective school-based substance abuse prevention. Prev Sci 2003;4:27-38.

61. Walton MA, Chermack ST, Shope JT, et al. Effects of a brief intervention for reducing violence and alcohol misuse among adolescents. JAMA 2010; 304:527.

62. Wilson SJ, Lipsey MW. School-based interventions for aggressive and disruptive behavior: update of a meta-analysis. Am J Prev Med 2007;33:S130-43.

63. WISQARS (Web-based injury Statistics Query and Reporting System). Query W. 2010. Available from: http://www.cdc.gov/injury/wisqars/index.html.

Accessed Feb 2, 2016.

64. Hahn R, Fuqua-Whitley D, Wethington H, et al. Effectiveness of universal school-based programs to prevent violent and aggressive behavior: a systematic review. Am J Prev Med 2007;33(2 Suppl):S114-29.

65. Sigel E. 66. Violence risk screening: predicting cyber violence perpetration and victimization. J Adolesc Health 2013;2:S53.

66. Sigel E, Hart J, Hoffenberg A, Dodge M. Development and psychometric properties of a violence screening tool for primary care. J Adolesc Health 2011;48:358-65.

67. Hayes DN, Sege R. FiGHTS: a preliminary screening tool for adolescent firearms-carrying. Ann Emerg Med 2003;42:798-807.
68. Borowsky IW, Mozayeny S, Stuenkel K, Ireland M. Effects of a primary care-based intervention on violent behavior and injury in children. Pediatrics 2004;114:e392-9.

69. Cunningham RM, Chermack ST, Zimmerman MA, et al. Brief motivational interviewing intervention for peer violence and alcohol use in teens: one-year follow-up. Pediatrics 2012;129:1083-90.

70. Alexander GL, McClure JB, Calvi JH, et al. A randomized clinical trial evaluating online interventions to improve fruit and vegetable consumption. Am J Public Health 2010;100:319.

71. McKay JR, Lynch KG, Shepard DS, et al. The effectiveness of telephone-based continuing care in the clinical management of alcohol and cocaine use disorders: 12-month outcomes. J Consult Clin Psychol 2004;72:967.

72. Damschroder LJ, Lutes LD, Goodrich DE, Gillon L, Lowery JC. A small-change approach delivered via telephone promotes weight loss in veterans: results from the ASPIRE-VA pilot study. Patient Educ Counsel 2010;79:262-6.

73. Moczygemba LR, Barner JC, Gabrillo ER, Godley PJ. Development and implementation of a telephone medication therapy management program for Medicare beneficiaries. Am J Health Syst Pharm 2008;65:1655-60.

74. Ranney ML, Choo EK, Cunningham RM, et al. Acceptability, language, and structure of text message-based behavioral interventions for high-risk adolescent females: a qualitative study. J Adolesc Health 2014;55:33-40.

75. Brener ND, Billy JO, Grady WR. Assessment of factors affecting the validity of self-reported healthrisk behavior among adolescents: evidence from the scientific literature. J Adolesc Health 2003;33: 436-57.

\section{Virtual Issue Editors}

Geriatrics: Scott Wilber, MD, Summa Health System (on behalf of the Academy of Geriatric Emergency Medicine)

Toxicology: Mark B. Mycyk, MD, Boston University School of Medicine

Ultrasound: Resa Lewiss, MD, University of Colorado (on behalf of the Academy of Emergency Ultrasound)

Injury Prevention: Rebecca Cunningham, MD, University of Michigan

Research Methodology \& Statistics: Craig D. Newgard, MD, MPH, Oregon Health \& Science University

EMS: David C. Cone, MD, Yale University School of Medicine

Education Research: Josh Kornegay, MD, Oregon Health \& Science University 